http://dx.doi.org/10.35381/racji.v6i10.1174

\title{
Sanción por abuso del Derecho en Ecuador
}

\section{Penalty for abuse of Rights in Ecuador}

\author{
Leonidas Alfredo Calderón-Proce \\ dq.leonidasacp21@uniandes.edu.ec \\ Universidad Regional Autónoma de los Andes, Quevedo \\ Ecuador \\ https://orcid.org/0000-0001-6690-4684 \\ Juan Carlos Arandia-Zambrano \\ uq. @uniandes.edu.ec \\ Universidad Regional Autónoma de los Andes, Quevedo \\ Ecuador \\ https://orcid.org/0000-0003-1152-104X \\ Luis Antonio Rivera-Velasco \\ uq.luisrivera@uniandes.edu.ec \\ Universidad Regional Autónoma de los Andes, Quevedo \\ Ecuador \\ https://orcid.org/0000-0003-2094-9566
}

Recepción: 11 de septiembre 2020

Revisado: 20 de octubre 2020

Aprobación: 18 de diciembre 2020

Publicación: 01 de enero 2021 


\title{
RESUMEN
}

La investigación tiene como objetivo analizar la sanción por abuso del derecho en Ecuador. Se generó desde una metodología descriptiva no experimental, abordándose una población de 30 profesionales del derecho de la ciudad de Quevedo - Ecuador. Los principales resultados se centraron en reconocer el abuso del derecho, a partir de agresiones de quienes en el ejercicio de poder abusaron de la situación jurídica y del derecho, se demostró como este exceso de límites de "derecho", vulneran a las partes procesales; se concreta además que a pesar de esta figura corresponde situarla dentro de los lineamientos generales de la ilicitud, se ha confundido con otras limitaciones de derechos como lo son la prohibición legal y el incumplimiento de obligaciones.

Descriptores: Derecho a la justicia; administración de justicia; aplicación de la ley. (Palabras tomadas del Tesauro UNESCO).

\begin{abstract}
The objective of the investigation is to analyze the sanction for abuse of rights in Ecuador. It was generated from a non-experimental descriptive methodology, addressing a population of 30 legal professionals from the city of Quevedo - Ecuador. The main results focused on recognizing the abuse of the right, based on the aggressions of those who in the exercise of power abused the legal situation and the right, it was demonstrated how this excess of limits of "right" violates the parties procedural; It is also specified that despite this figure it corresponds to place it within the general guidelines of illegality, it has been confused with other limitations of rights such as the legal prohibition and the breach of obligations.
\end{abstract}

Descriptors: Right to justice; administration of justice; law enforcement. (Words taken from the UNESCO Thesaurus). 


\section{INTRODUCCIÓN}

El abuso del derecho suele constituirse en un flagelo que suele pasar desapercibido desde una sanción directa y codificada en las leyes ecuatorianas, en este sentido, al incurrir en abuso por parte de un funcionario público o privado que debe accionar justicia en su proceder, se suele penalizar con infracciones derivadas de una acción calificada como crimen, delito o falta, dejando a la deriva o interpretación subjetiva moral, lo entendido como abuso en el derecho, por consiguiente:

Se configura el abuso del derecho cuando se da una desviación o distorsión del espíritu de los derechos, sea porque se ejercen con la fría intención de causar daño, porque no existe un interés actual y propio, o porque se desarrollan con evidente imprudencia o negligencia (Hernández-Velasco \& Pardo-Martínez, 2014).

Por tanto, debe considerarse como abuso de derecho todo acto mal intencionado ejecutado por personas conocedoras o no del marco legal del Estado Ecuatoriano, con mayor responsabilidad evidente en quien lo conoce y lo desvirtúa en razón de obtener beneficios atropellando la buena voluntad, procedimientos administrativos - jurídicos, violando la ley, agrediendo psicológica o físicamente a terceras personas, así como quien se vale de su poder o investidura para coaccionar hasta lograr un determinado fin en afectación o detrimento de otros o instituciones.

En el marco de cambio de un Estado liberal con modelo constitucional a un Estado Constitucional de Derechos y Justicia, trajo como consecuencia un cambio de cultura jurídica para el efecto, la Constitución de la República del Ecuador del año 2008, en su esencia garantista, se enlistan derechos inmersos al debido proceso, que es la columna vertebral de los principios procesales, para brindar eficacia a la seguridad jurídica, de ese modo:

Se refiere al principio de buena fe y lealtad procesal y ordena: En los procesos judiciales las juezas y jueces exigirán a las partes y a sus abogadas o abogados que observen una conducta de respeto recíproco e intervención ética, teniendo el deber de actuar con buena fe y lealtad. Se sancionará especialmente la prueba deformada, todo modo de abuso del derecho, el empleo de artimañas y procedimientos de mala fe para retardar 
indebidamente el progreso de la Litis (artículo 26 del Código Orgánico de la Función Judicial de Ecuador).

Por consiguiente, la doctrina establece tres modalidades en las que una persona puede acudir en el ejercicio del abuso del derecho, estas son; en el momento que hacer respetar frente a terceras personas, hacer respetar en vías jurídicas y el disfrute del contenido. En razón de lo descrito, la investigación tiene como objetivo analizar la sanción por abuso del derecho en Ecuador.

\section{MÉTODO}

La investigación se generó desde una metodología descriptiva no experimental, abordándose una población de 30 profesionales del derecho de la ciudad de Quevedo Ecuador, quienes fueron encuestados mediante un instrumento tipo cuestionario de varias alternativas de respuestas, siendo validado por juicio de expertos y cálculo de coeficiente Alfa de Cronbach con resultado de 0,86 siendo catalogado confiable para su aplicación, de ese modo, una vez recopilado los datos, se procedió al análisis de los mismos, mediante estadística descriptiva para generar una distribución en frecuencias y porcentajes.

\section{RESULTADOS}

Según los resultados obtenidos el $82 \%$ de la población encuestada considera que en los procesos judiciales es frecuente el abuso del derecho por las partes, mientras un $18 \%$ considera que no es así.

El 75\% de las encuestas arrojan que, si están de acuerdo que el Código Orgánico de la Función Judicial, al establecer el principio de abuso del derecho deja libre sus consecuencias a la doctrina, mientras que el $25 \%$ contradice aquello.

El 92\% arroja que es necesario efectuar una reforma al Código Orgánico de la Función Judicial estableciendo sanciones para la parte que abuse del derecho, para de este modo garantizar el principio de la tutela efectiva. 


\section{DISCUSIÓN}

De los resultados obtenidos de las encuestas efectuadas, se deduce que el derecho, siempre, ha sido víctima de agresiones de quienes, en ejercicio de algún poder, abusaron de la situación jurídica y del derecho (Fuerte-Carrera, et al., 2020), esto puede ser debido a que se excedió de los límites de su "derecho", esta vulneración a la que están expuestas las partes procesales, se lo conoce como abuso del derecho (López-Díaz, 2012).

Esta vulneración, consiste en la utilización de los medios que provee la ley para ejercer un derecho, con fines distintos a los que persigue la norma y la justicia; es un problema social jurídico, que se extiende a los ámbitos del sistema legal (Castro-Pizarro, et al. 2019), promovido por causas como la debilidad de la Ley a consecuencia de su oscuridad o vacíos, la mala fe y deslealtad de las partes procesales en la relación jurídica que ejercen su derecho y al establecer las consecuencias y responsabilidades se garantizará la tutela judicial efectiva (Rutherford, 2013).

La legislación ecuatoriana en el (Código Orgánico de la Función Judicial), establece el abuso del derecho, dentro del principio de buena fe y lealtad procesal, pero, no determina una sanción concreta ante el cometimiento de esta infracción, sin embargo, se podría cuantificar el daño y perjuicio causado, para de esta manera los Jueces puedan emitir una sanción, considerando que, al momento de cometer abuso del derecho, se está cometiendo un daño y perjuicio al adversario (Comanducci, 2011).

Es por este motivo que, los Asambleístas deberían reformar el Código Orgánico de la Función Judicial, en este sentido, a fin de que, esté en total congruencia con este nuevo paradigma jurídico como es el abuso del derecho, en cuanto, a la sanción que deben imponer los administradores de justicia (Tamayo-Vásquez \& Pino-Loza, 2019), de ese modo, podrá corregirse los vacíos existentes en la ley sobre el abuso de derecho, siendo en esencia proponer una sanción, además de una medida restaurativa del perjuicio generado desde el abuso de poder (Morgestein-Sánchez, 2019). 


\section{CONCLUSIONES}

El abuso del derecho es un ilícito civil que encamina a la inmoralidad de las normas, puesto que, por ejemplo, en una acción civil, el actor se aleja de su fin legítimo, para degenerar y producir un daño al demandado.

Desde el diagnóstico del estado actual y con la aplicación de la metodología empleada, se concluye que la Jurisprudencia ecuatoriana trata al abuso del derecho mientras los accionantes como fue en el caso de análisis confunde el abuso del derecho con otras figuras que son especies del género ilícito.

Realizado el análisis jurídico se concreta que a pesar de que se ha dicho que esta figura corresponde dentro de los lineamientos de la ilicitud, se encuentra que se ha confundido a esta figura con otras limitaciones a los derechos como lo son la prohibición legal, el incumplimiento de obligaciones, e incluso se la ha confundido con la fuerza, que está dentro de los vicios del consentimiento.

\section{FINANCIAMIENTO}

No monetario.

\section{AGRADECIMIENTO}

A la Universidad Regional Autónoma de los Andes, Quevedo; por motivar el desarrollo de la Investigación.

\section{REFERENCIAS CONSULTADAS}

Castro-Pizarro, J, Masache-Romero, C, \& Durán-Ocampo, A. (2019). La aplicación del Derecho Público en el Ecuador [The application of Public Law in Ecuador]. Revista Universidad y Sociedad, 11(4), 350-360.

Código Orgánico de la Función Judicial de Ecuador. Registro Oficial Suplemento 544 de 09-mar.-2009. Última modificación: 22-may.-2015. https://n9.cl/wm4o 
Comanducci, P. (2011). El abuso del derecho y la interpretación jurídica [Abuse of Right and Legal Interpretation]. Revista de Derecho Privado, (21), 107-118.

Constitución de la República del Ecuador del año 2008. Registro Oficial 449 de 20-oct2008. Última modificación: 13-jul-2011. https://n9.cl/hd0q

Fuerte-Carrera, J., Arrias-Añez, J., \& Pupo-Kairuz, A. (2020). Análisis sobre el peculado y la delincuencia organizada en los procesos de contratación pública emergente [Analysis of embezzlement and organized crime in emerging public procurement $\begin{array}{lll}\text { processes]. IUSTITIA } & \text { SOCIALIS, } & \text { 783-797. }\end{array}$ http://dx.doi.org/10.35381/racji.v5i2.1065

Hernández-Velasco, H. E., \& Pardo-Martínez, O. (2014). La aplicación de la teoría del abuso del derecho en la jurisprudencia colombiana [The application of the theory of abuse of rights in Colombian jurisprudence]. Opinión Jurídica, 13(26).

López-Díaz, P. (2012). El abuso del derecho de opción del acreedor y su importancia en la construcción de un sistema equilibrado de remedios por incumplimiemto contractual [The abuse of the right of the creditor's option and its importance in building a balanced system of remedies for breach of contract]. Revista chilena de derecho privado, (19), 13-62. https://dx.doi.org/10.4067/S0718$\underline{80722012000200002}$

Morgestein-Sánchez, W.I. (2019). El principio de la prohibición del abuso del derecho. Una referencia especial al abuso del derecho de voto de los asociados minoritarios en las compañías mercantiles colombianas [The principle of the prohibition of abuse of rights. A special reference to the abuse of the voting rights of minority associates in Colombian mercantile companies]. Revista Jurídicas, 16(1), 104-119. https://doi.org/10.17151/jurid.2019.16.1.7

Rutherford, R. (2013). La "aemulatio" y el abuso del derecho ["Aemulatio" and Abuse of Rights]. Revista de estudios histórico-jurídicos, (35), 635651. https://dx.doi.org/10.4067/S0716-54552013000100020

Tamayo-Vásquez, F., \& Pino-Loza, E. (2019). Derechos Humanos de los niños, niñas y adolescentes en los procesos Arbitrales [Human Rights of children and adolescents in arbitration proceedings]. IUSTITIA SOCIALIS, 4(7), 97-114. http://dx.doi.org/10.35381/racii.v4i7.357 
Iustitia Socialis. Revista Arbitrada de Ciencias Jurídicas.

Año VI. Vol. VI. N 10. Enero - Junio. 2021

Hecho el depósito de Ley: FA2016000064

ISSN: 2542-3371

FUNDACIÓN KOINONIA (F.K). Santa Ana de Coro, Venezuela

Leonidas Alfredo Calderón-Proce; Juan Carlos Arandia-Zambrano; Luis Antonio Rivera-Velasco

(C2021 por los autores. Este artículo es de acceso abierto y distribuido según los términos y condiciones de la licencia Creative Commons Atribución-NoComercial-CompartirIgual 4.0 Internacional (CC BY-NC-SA 4.0) (https://creativecommons.org/licenses/by-nc-sa/4.0/). 